\title{
POSSIBILITY OF APPLYING BIM IN SYRIAN BUILDING PROJECTS
}

\author{
Sonia Ahmed ${ }^{1,2}$, Petr Dlask ${ }^{1}$, Mohamed Shaban ${ }^{3}$, Omar Selim ${ }^{2}$ \\ ${ }^{1}$ Czech Technical University in Prague, Czech Republic; \\ ${ }^{2}$ BIMarabia, United Kingdom; ${ }^{3}$ AL-Baath University, Syria \\ sonia_ahmad24@yahoo.com, shabanm85@gmail.com,omar.selm@gmail.com
}

\begin{abstract}
As a developing country and according to the situations of war and siege experienced by it Syria has a good percentage of the Middle East nations in the field of adopting new technologies and systems. This research demonstrates the awareness of BIM between Syrian engineers in the public sector and the possibility of mandating BIM in the near future. A quantitative statistic did achieve the research aim using both open and closed questionnaire. The research showed that Syrian construction and engineering workers know a little about the BIM. However, more than $44 \%$ via 89 respondents reported that the full adoption of BIM in Syria will be within the next five years with the emphasis on the need to develop the BIM standard before the start. About $61 \%$ of the respondents believe that BIM can be useful in the design stage, while $21 \%$ indicated that they can implement BIM in both design and construction stage of the project. Whatever the case, $49 \%$ of respondents found that BIM can solve 50-75\% of the current building problems. Respondents identified the most expected benefits of BIM, also barriers and challenges that hinder the application of BIM: economic, technical, organizational, legal and human challenges. In addition to that, the risks were explained that may occur within the projects implemented using BIM. This study in association with Syrian organizations and universities showed the tendency towards the philosophy of building information modeling for the new generation of Syrian engineering. About $37 \%$ of the respondents considered Syria government to be the main engine for the BIM adoptions; while more than $22 \%$ believe that the designer is the main engine to adopt and convince others about the benefits of BIM during the building projects life cycle. Unfortunately, due to the lack of the budget allocated for the training and rehabilitation of employees, or fear of the high cost of adopting this technology and the use of programs $31 \%$ of staff rely on self-training, and only $24 \%$ of them receive formal training in addition to their effort. Researchers believe that this research will be the first step towards soft moving to BIM in Syrian projects.
\end{abstract}

Keywords: BIM, building, modelling, quantitative statistic.

\section{Introduction}

Building problems in most of the world are general with some exceptions depending on the nature, policy, and privacy of the work in each country [1]. To achieve the best performance, the client satisfaction must arrive by meeting the quality of the project within the specified cost and time [2]. The aim of this study is to explain the possibility of using the BIM technology, which achieved excellent results for the countries that adopted it; in Syrian building sector. Eastman offered BIM as "The use of computers instead of drawings in building design" [3]. BIM also can be required as a procedural and technological shift in the AEC industry [4]. Penttilä in 2006 said that, if there was no BIM, another system would have been found in any name and may have been abbreviated BIM also or virtual building [5].

Implementation strategies have been established for the use of BIM on construction projects worldwide. For example, the UK government has mandated the use of BIM level 2 for government projects by 2016 [6]. According to [7] "hundreds of organizations around the world adopted BIM and gained its benefits, met clients and users' satisfaction and increased their profits by 5-12\%". Most of these countries have previously suffered from the constraints of adopting the BIM because the traditionalists refused to change their way of working; in addition to this fact, [8] cited that "the 2012 McGraw Hill Construction Smart Market Report showed that $71 \%$ of designers and contractors in the US are now using BIM to some extent". And according to the NBS 2017: over the six years, BIM adoption has increased over $8 \%$ each year, on average". So, given the impressive results currently reading in monthly and annual reports of the significant benefits and continuous improvements of all parties involved in building projects around the developed world, and based on the results of research and critical reviews in the building industry, and the similarity and significant convergence of the imbalances and problems between most of the developed world and the third world countries [3], a practical step has been taken in improving the reality of building in the Arab world by introducing the benefits of implementing the BIM within building projects, and the search for the most critical barriers and challenges and plans to avoid it. Also the multi-national firms that have multiple offices across the Middle East region imposed a wider adoption of BIM in construction processes there, but according to 
[10] only $20 \%$ of AEC organizations in the Middle East are using BIM or are in the process of adopting BIM, with most professionals within this region still looking at BIM just as an advanced AutoCAD tool; in addition to the fact that the transitions to new instruments are always difficult. Raising awareness related to the benefits of BIM and increasing the training opportunities in the Middle East are necessary in order to allow all stakeholders to benefit substantially from BIM.

According to the war conditions; Syria was an exception, but there is understanding of the need for the introducing modern technologies and advanced management tools to building projects in Syria, like other countries that suffered from poor performance and lack of technology in the past [11]. Beside the desire of the Syrian engineers and government to reconstruct Syria with local hands and expertise, BIM now has a study plan at all undergraduate, Master, Ph.D. degree courses at Syrian universities. In addition, there are individual and local training, conferences, workshops etc. So, a gradual transition towards the adoption of BIM has really started in Syria.

\section{Search Problem}

Although the adoption of Building Information Modelling is used widely all over the world, it is considered a new philosophy in Syria. And the next reconstruction stage needs using of new technologies like BIM, which form the suitable solution for this stage.

\section{Materials and methods}

As a first step, the authors began reviewing literature reviews on the implementation of BIM in the Middle East and worldwide. To achieve the objective of this study quantitative statistic of the possibility of the application of BIM in the Syrian building sector was done. An online questionnaire was built; it is the fastest and easiest way to have the respondents' opinion, and it could be easily accessed by construction professionals anywhere in the under war region. Also, an open questionnaire was created by proceeding face to face meeting with the aim to explain BIM and to enhance the closed questionnaire's results. The questionnaire general structure contained a suitable title, brief introduction and explanation of the research. It consisted of thirty-four questions - clear, simple and flowing smoothly on to the next. Respondents were 89 people, they were chosen through probability sampling procedures. It is a perfect percentage and represents a segment of the Syrian engineers in several regions and reflects the Syrian position in the current circumstances. The questions determined the knowledge about the modelling of building information in the engineering community - the excepted benefits of BIM, defined barriers and challenges that hinder its application including economic, technical, organizational, legal and human challenges. In addition, some information about: the future of BIM and the potential for adoption in the coming years, the risks that may occur within the projects implemented using BIM, who is responsible for approval from the respondents and other answers that we will be discussed in detail. A Likert scale was used; it consisted of five points 1 - strongly agree, 2 - agree, 3 - neutral, 4 - disagree, 5 - strongly disagree. For some questions the respondents could choose more than one answer. In addition, some questions gave the respondents the freedom of giving a different answer by the option of "other (please specify)".

The pilot study was completed to test the survey instrument. Invitations were sent to construction professionals in the Syrian construction industry by emails, LinkedIn, and BIMarabia website. The invitation contained a description of the research and its aim, and the link at the end of the invitations, which takes respondents to the online questionnaire. The questionnaire has targeted universities, consulting firms, contractors, manufacturers, construction managers and site engineers, which belong to both the public and the private sector for a more accurate result.

\section{Results and discussion}

The scientific degrees of respondents varied from Bachelor to Diploma, Master, and Ph.D. in Engineering in most of its specializations, the highest of which is civil engineering (60\%), followed by architectural $(25.8 \%)$, mechanical, electrical and others. The highest percentage of respondents were designers, project managers, consultants and other working groups in several different companies: studies, Execution, Syrian Universities, and Engineers Syndicates located in several governorates, in addition, some private engineering offices, buildings belonging to the Ministry of Health, Culture, Tourism, Ministry of Public Works, Ministry of Housing and others. 


\section{Survey findings}

In general, the study showed that the percentage of engineering knowledge about Building Information Modelling is represented by about $50 \%$ of the respondents. The results of the survey show that (10) out of (42) engineers have worked on at least two projects related to modelling, these results are right, relative to the novelty of this issue in the Middle East in general. The experience of the highest proportion of respondents in the engineering work exceeded 15 years, knowing that $20 \%$ of them are still in the first stage after graduation with years of experience ranging from 2 to 5 years. As the survey shows, $30 \%$ of the respondents work in the field of residential building (designers, project managers, consultants) and $26 \%$ as the second rank for the education sector, represented by the Syrian universities spread throughout the Syrian areas. Only $5 \%$ of the respondents work in the industrial sector. Only about $20 \%$ use the 3D software in more than $90 \%$ of their projects. $30 \%$ of the respondents use the architectural and structural Revit, only $13 \%$ use the MEP, but $75 \%$ still use AutoCAD, with a note that some of them use AutoCAD beside of using of Revit. Fig.1. shows that $56 \%$ of respondents consider themselves to be BIM users at present, although they often use only one program, the Revit. Their vision differed to the definition of BIM, but the majority (53.7\%) felt that BIM was a new technology and technic in work.

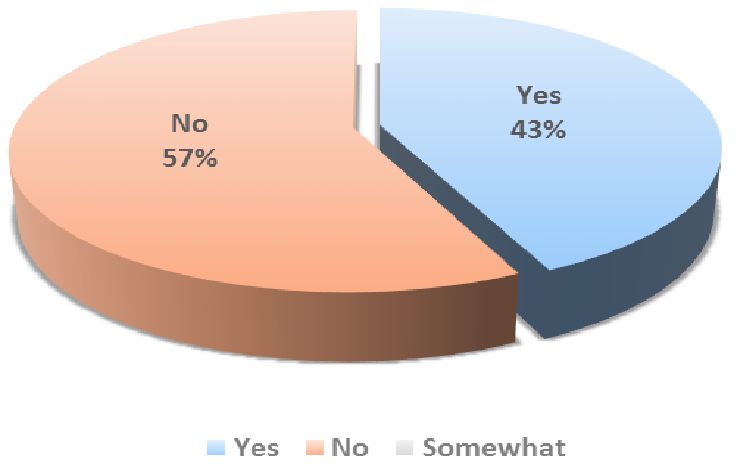

Fig. 1. Percentage of BIM users, percent \%, source Authors, 2017

Many of the participating engineers confirmed the electronic delivery as a solution for not losing and damaging the information, and the ability to use it faster, if needed later. In responders' opinion, $63 \%$ of the companies and individuals surveyed used both paper and electronic documentation, the use of electronic copies was only $15 \%$. Only $50 \%$ of users find that their companies believe in cooperative work and this greatly facilitates the possibility of going to work with the BIM. Unfortunately, decision-makers in most Syrian companies know little about the importance of this technology with a weakness of the budget allocated for the training of employees and fear of the high cost of adopting this technology. Based on that, $31 \%$ of the staff rely on individual training, and $24 \%$ of them receive formal training in addition to their effort. See Table 1.

Table 1

The most commonly used method for delivering project data and outputs, source: authors, 2017

\begin{tabular}{|c|c|}
\hline Answer choices & Responses, \% \\
\hline Formal training for a specified period of working hours & 15 \\
\hline Engineers take formal training outside working hours & 16 \\
\hline Combination of formal and individual training & 24 \\
\hline Working with a team of specialists on a realistic project & 19 \\
\hline Individual training & 31 \\
\hline There is no training & 13 \\
\hline Other & 3 \\
\hline
\end{tabular}

$28 \%$ believe that despite the low rate of implementation of BIM in Syrian projects and its rarity in many companies, the adoption of this technology will be during the next five years. About $35 \%$ of the respondents believe that this should be compulsory and under the guidance of the government, which is considered by about $37 \%$ of the respondents to be the primary engine for the adoption of the BIM. While more than $22 \%$ believe that the designer is the main engine to adopt and convince others 
about the benefits of building information modeling (BIM) as part of construction projects in Syria. Most of the countries around the world that have entered the BIM system have sought to set corporate standards and then move to general national principles and standards, where there are now more than 70 codes around the world for the BIM system and its uses. About the importance and necessity of having a BIM code, $29 \%$ believe that the process of setting an individual standard to deal with the principles and techniques of BIM is fundamental, while another $50 \%$ find it essential and $9 \%$ find it not very important.

Another set of questions focused on defining at any stage of the project lifecycle whether it is now possible to apply the BIM system to the Syrian construction industry. The findings as shown in Fig. 2 . indicate that $61 \%$ of the respondents believe that BIM can be useful in the design stage, while $21 \%$ indicated that they can implement BIM in both design and construction stage of the project. Unfortunately, $8 \%$ said that it is impossible to use BIM now.

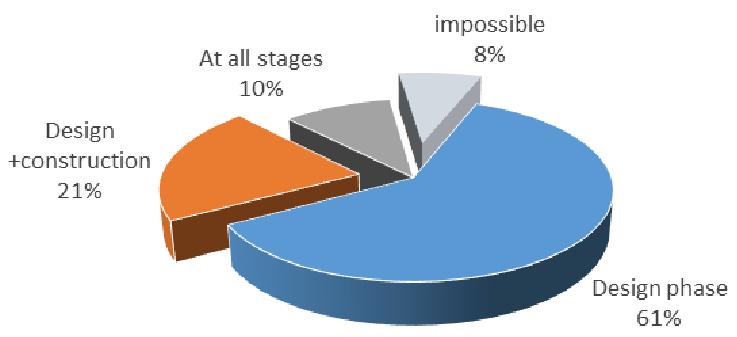

- Design phase - Design +construction $\|$ At all stages

Fig. 2. Best stage to apply BIM to Syrian construction industry, percent \%, source: authors, 2017

As a result of the importance of risks facing the traditional work and the need to identify, manage and distribute responsibility among the participating parties, it was necessary to mention the most important risks that may face the projects that will be implemented using the BIM [12].

- Risks of lack of clarity (unclear specifications, customer requirements, required quality of achievements).

- Misappropriateness of information and significant errors in construction works.

- 3D models and their 2D exports have not updated due to lack of cooperation between the parties of the project. See Table 2.

Main risks facing projects implemented using BIM, source: author results, 2017

\begin{tabular}{|c|c|}
\hline Answer choices & Responses \% \\
\hline Risk of lack of clarity & 45.0 \\
\hline No evidence to support supply chine experience in the BIM projects & 28.0 \\
\hline Lack of cooperation between the parties of the project & 37.0 \\
\hline Wrong transmission of the information, and consequently errors on site & 39.6 \\
\hline Accidents and inaccuracies of technology & 20.0 \\
\hline Risk of non-compliance with contract terms & 30.0 \\
\hline Inaccuracy in information provided by tenders for estimating quantities and costs. & 20.0 \\
\hline Delay in schedules & 13.0 \\
\hline
\end{tabular}

A survey in the United States and Europe confirmed that BIM adoption rose dramatically from $28 \%$ in 2007 to $71 \%$ in 2012 and is still booming to the present [13]. The responses in this survey emphasized the problems of cost overruns and delays, rework, and frequency of change orders as the most current Syrian building problems; $49 \%$ of the respondents saying that BIM can solve these problems and the most expected benefits from the BIM application were assessed and ranked in the top five. 
- Change in a specific place of design followed by an automatic change in all sections and interfaces associated with it.

- Detect design errors, conflicts and minimize rework.

- Save the cost of the project.

- Enable collaboration between different project parties and improve communication.

- Save the project time.

To achieve the analysis aim the barriers and challenges facing BIM implementation in Syrian construction environment had to be investigated. As shown below, the respondents identified the most barriers and obstacles that hinder the application of BIM in five sets: economic, technical, organizational, legal, and human challenges.

- Economic challenges.

- Lack of demand for BIM by other parties involved in the projects.

- Lack of clarity of investment due to BIM application.

- The recruitment of BIM specialists and additional staff.

- Technical challenges.

- The need for a strong Internet connection and uninterrupted power.

- Believing that existing techniques are adequate, there is no need to apply BIM.

- Insufficient standards and protocols related to BIM.

- Interoperability as one of the standard challenges of BIM [14].

- Organizational challenges.

- Weak cooperation between different disciplines.

- Inadequate government efforts to adopt and implement BIM.

- The need to manage sophisticated data with the level of evolution of the model.

- Legal challenges.

- The need to formulate BIM contracts.

- Lack of clarity of responsibilities between project parties.

- Human challenges.

- Lack of experience and lack of staff trained for BIM programs.

- Weak knowledge of the benefits offered by BIM.

- The sharp resistance to change, especially the aged persons, and the engineer's affection to their familiar programs.

The last question in this search focused on the respondent's opinion of what are the most important items that serve in the localization of building information modelling technology? The most important answers according to their frequency were as follows.

- To raise awareness of cooperation culture between different parties.

- Government policy to make the use of BIM technology mandatory through the development of individual laws.

- Establish an educational base for BIM technology by making it part of the curricula of universities.

- Provide government support for the implementation of BIM technology in private companies and institutions.

- Allocate financial funding to support the costs of BIM technology.

- Engaging with international specialists with expertise in BIM technology.

- Development of contracts and legal materials governing the use of BIM technology.

\section{Result discussion}

From the NBS reports and other statistics in this field, when compared to the questionnaire results, it can be said that BIM adoption in Syria started as in so many countries from the education sector. And it is currently being implemented in certain aspects of construction projects especially during the design stage. During one of the necessary meetings between the authors and the manager of GCEC (The General Consultant and Engineering Company) as an open questionnaire, it was found that the company by its manager made the decision of beginning a pilot project by using BIM. $43 \%$ of 
the responders said that they used BIM, more of them know only little about BIM and use only one BIM software - Revit. However, the authors presented their desire in forming the BIM team in this company and were going step by step towards completing the first pilot project. From the fact that (10) out of (42) engineers have worked on at least two projects related to modeling, $43 \%$ of the respondents use the architectural and structural and MEP Revit, Syrian engineers were able to determine the big benefit that could be accepted from using BIM at the design stage. Some of them know the BIM technology as they like to identify it from their work in some Arabic countries as Qatar, Arab Emirate, which is considered the BIM leader in the Middle East [10].

They learned from their experience of using BIM tools how it minimizes the most important problem such as cost and time overrun. Consequently, it can be indicated that the return on BIM investment will be as a motive for companies' owners to implement BIM in future. In addition, the respondents observed that the implementation of BIM will be able in the next five years. Furthermore, they also identified the barriers and challenges that hinder the application of BIM: economic, technical, organizational, legal, and human challenges. The experience of the highest proportion of respondents in the engineering work exceeded 15 years, knowing that $20 \%$ of them are still in the first stage after graduation with years of experience ranging from 2 to 5 years. As the survey shows, $30 \%$ of the respondents work in the field of residential construction and $26 \%$ as the second rank for the education sector, represented by the Syrian universities spread throughout the Syrian areas. Unfortunately, those with experience over 15 years reject BIM technology; they do not like to change the way they used to work. However, the authors tried to explain to the traditional engineers that they will have big experience, which companies always need.

\section{Conclusions}

1. Respondents were 89 people representing the segment of the Syrian engineers in several regions and reflect the Syrian position in the current circumstances.

2. About $35 \%$ of the respondents believe that this should be compulsory and under the guidance of the government.

3. More than $22 \%$ believe that the designer is the main engine to adopt and convince others about the benefits of building information modeling (BIM) as part of construction projects in Syria.

4. $49 \%$ of respondents found that BIM can solve 50-75\% of current buildings problems. $61 \%$ of the respondents believe that BIM can be useful in the design stage, while $21 \%$ indicated that they can implement BIM in both design and construction stage of the project.

5. In Syria of BIM still is not adopting, but it may be mandated during the next 5 years.

6. $43 \%$ of respondents are using Revit (Architectural, Structural, MEP) and consider themselves as BIM users.

7. Furthermore, the main perceived obstacles to BIM implementation were identified as economic, technical, organizational, legal, and human challenges.

8. The authors noted the fact that $15 \%$ only use electronic documentation. Also only $24 \%$ of the staff received formal training in addition to their effort.

9. $29 \%$ believe that the process of setting an individual standard to deal with the principles and techniques of BIM is fundamental, while another $50 \%$ find it essential and $9 \%$ find it not very important.

\section{Acknowledgments}

This work was supported by the Grant Agency of the Czech Technical University in Prague, grant No. SGS17/121/OHK1/2T/11

\section{Footnote}

1. BIMarabia: the first e-magazine specialist on BIM. 2015. [online]. http://bimarabia.com/bimarabia-english/

2. BIMdictionary: available at www.bimdictionary.com

3. Succar B.: Founder of BIM Think-space (Oct 2005), available at http://www.bimthinkspace.com/about.html/ 


\section{References}

[1] Ahmed S., Dlaska P., Hassan B., Beshara M. "Pre-Cast Concrete, a Key Option for the Reconstruction Phase after War", Procedia Engineering, 2017, pp. 211-219. DOI: 10.1016/j.proeng.2017.08.074.

[2] Ahmed S., Hasan B., Jrad F., Dlask P. Analyzing the Change Orders Impact on Building Projects. Journal of Engineering and Applied Sciences, 11(7), 2016, pp. 1532-1537. [online][19.03.2018] Available at: http://medwelljournals.com/abstract/?doi=jeasci.2016.1532.1537

[3] Eastman C. The use of Computer instead of Drawings in Building Design. American Institute of Architecture, 63(3), 1975, pp. 46-50. [online] [19.03.2018] Available at: https://www.academia.edu/8519182/The_Use_of_Computers_Instead_of_Drawing_in_Building_ Design_-_1975

[4] Succar B. Building information modeling framework: A research and delivery foundation for industry stakeholders. Automation in Construction, 18, 2009, pp. 357-375.

[5] Penttilä H. Describing the Changes in Architectural Information Technology to Understand Design Complexity And Free-Form Architectural Expression. ITcon, 11, 2006, pp. 395-408. [online] [19.03.2018] Available at: http://www.itcon.org/2006/29

[6] Constructing Excellence. UK Industry Performance Report: Based on the UK Construction Industry Key Performance Indicators. Constructing Excellence, 2008.

[7] Jernigan F. BIG BIM little bim - the practical approach to building information modeling Integrated practice did the right way! 1st Edition, Kindle Edition. [online] [19.03.2018] Available at: https://www.amazon.com/BIG-BIM-little-bim-information-ebook/dp/B0010AE7PS.

[8] Moreno C., Olbina S., Issa R. School of building construction, University of Florida, USA, 2013, [online] [19.03.2018] Available at: https://doi.org/10.1061/9780784413616.056

[9] NBS. NBS National BIM Report. United Kingdom: RIBA Enterprises, 2017. [online] [19.03.2018] Available at: https://www.thenbs.com/knowledge/nbs-national-bim-report-2017

[10] Gerges M., Austin S., Mayouf M., Ahiakwo O., Jaeger M., Saad A., Gohary T.E. An investigation into the implementation of Building Information Modeling in the Middle East, ITcon Vol. 22, 2017, pp. 1-15. [online] [19.03.2018] Available at: http://www.itcon.org/2017/1

[11] Mia R. Performance Management for Syrian Construction Projects. International Journal of Construction Engineering and Management. 5(3), 2016, pp. 65-78. DOI: 10.5923/j.ijcem.20160503.01.

[12] Matejka P., Tomek A. "Ontology of BIM in a Construction Project Life Cycle". Procedia Engineering, Elsevier, 2017. [online] [19.03.2018] Available at: https://doi.org/10.1016/j.proeng.2017.08.065

[13] Associated General Contractors of America. The Contractor's Guide to BIM, 1st edition. Las Vegas: AGC Research Foundation publisher, 2015. [online] [19.03.2018] Available at: https://www.engr.psu.edu/ae/thesis/portfolios/2008/tjs288/Research/AGC_GuideToBIM.pdf

[14]Bouška R. Evaluation of Maturity of BIM Tools across Different Software Platforms. Procedia Engineering, 2016, 481 p. 